\title{
The dark halo technique in the oeuvre of Michael Sweerts and other Flemish and Dutch baroque painters. A 17th c. empirical solution to mitigate the optical 'simultaneous contrast' effect?
}

Kirsten Derks ${ }^{1,2,3 *}$, Geert Van der Snickt ${ }^{2,3}$, Stijn Legrand ${ }^{2,3}$, Katlijne Van der Stighelen ${ }^{1}$ and Koen Janssens ${ }^{2,3}$

\begin{abstract}
Although the topic is rarely addressed in literature, a significant number of baroque paintings exhibit dark, halo-like shapes around the contours of the dramatis personae. Close examination of both finished and unfinished works suggests that this intriguing feature was a practical tool that helped the artist in the early painting stages. When applying the final brushwork, the halo lost its function, with some artists undertaking efforts to hide it. Although their visibility might not have been intended by the artists, today this dark paint beneath the surface is partially visible through the upper paint layers. Moreover, the disclosure of many halos using infrared photography (IRP), infrared reflectography (IRR) and macro X-ray fluorescence imaging (MA-XRF), additional to those that can be observed visually, suggests that this was a common and established element of 17th-century painting practice in Western Europe. Building on an existing hypothesis, we argue that halos can be considered as a solution to an optical problem that arose when baroque painters reversed the traditional, 15th- and 16th-century painting sequence of working from background to foreground. Instead, they started with the dominant parts of a composition, such as the face of a sitter. In that case, a temporary halo can provide the essential tonal reference to anticipate the chromatic impact of the final dark colored background on the adjacent delicate carnations. In particular, we attempt to clarify the prevalence of dark halos as a response to optical effects such as 'simultaneous contrast' and 'the crispening effect', described in literature only centuries later. As such, the recently termed 'ring condition' can be seen as the present-day equivalent of the 'halo solution' that was seemingly empirically or intuitively developed by 17 th-century artists. Modern studies in visual perception proves that by laying a black ring around a target color, the optical impact of a surrounding color can be efficiently neutralized. Finally, by delving into works by Michael Sweerts, it becomes clear that resourceful artists might have adapted the halo technique and the underlying principles to their individual challenges, such as dealing with differently colored grounds.
\end{abstract}

Keywords: Seventeenth century, Painting technique, Flanders, Netherlands, MA-XRF scanning

\footnotetext{
*Correspondence: kirsten.derks@kuleuven.be

${ }^{1}$ Faculty of Arts, Research group Art History, KU Leuven, Blijde Inkomststraat 21, 3000 Leuven, Belgium

Full list of author information is available at the end of the article
}

\section{Introduction}

The research in this paper was initiated by an intriguing feature that was observed during a systematic study of paintings by Michael Sweerts. This survey is part of a larger study into the painting techniques employed by baroque artists based in Brussels, of which Sweerts
Springer Open

(c) The Author(s) 2021. Open Access This article is licensed under a Creative Commons Attribution 4.0 International License, which permits use, sharing, adaptation, distribution and reproduction in any medium or format, as long as you give appropriate credit to the original author(s) and the source, provide a link to the Creative Commons licence, and indicate if changes were made. The images or other third party material in this article are included in the article's Creative Commons licence, unless indicated otherwise in a credit line to the material. If material is not included in the article's Creative Commons licence and your intended use is not permitted by statutory regulation or exceeds the permitted use, you will need to obtain permission directly from the copyright holder. To view a copy of this licence, visit http://creativecommons.org/licenses/by/4.0/. The Creative Commons Public Domain Dedication waiver (http://creativeco mmons.org/publicdomain/zero/1.0/) applies to the data made available in this article, unless otherwise stated in a credit line to the data. 
is one of the most prominent [1]. Technical and art historical research into 17th-century art of the Southern Netherlands has mostly focused on Antwerp as an artistic center. With this research project, we attempt to gain more insight into the art production in other regions of the Spanish Netherlands. Michael Sweerts (1618-1664) can be considered one of the most creative and enigmatic 17th-century artists originating from Brussels; however, not much is known about him or his working methods. By analyzing a relevant sample of his oeuvre with macro $\mathrm{X}$-ray fluorescence scanning (MA-XRF), we hope to gain more knowledge about his materials, techniques and methods, and by extension about other Brussels baroque artists as well.

In the context of the aforementioned research, Sweerts' Peasant Family with a Man Defleaing Himself, shown in Fig. 1A, was studied. The composition of this bamboccianti-like painting in the Mauritshuis collection, shows six figures in a landscape with a barn. On the right side of the composition, a woman and a girl are depicted, standing with their back to the viewer. The upper body of the mother is painted against the background sky. During the visual examination, a halo-like pale shape around the mother figure immediately drew the attention. As shown in Fig. 1B, the paint of the sky directly adjacent to this figure displays a slightly lighter tone [2]. Surprisingly, the infrared reflectogram (IRR) revealed the seemingly contradictory presence of a carbon rich (thus dark) layer below the paint surface (Fig. 1D). Sweerts seems to have blocked out the contours of the main figures with a dark paint in an early stage of the painting process. These broad contours had already been observed during previous conservation treatments and are described in various conservation reports [3]. This underlying halo in the IRR seems to be the dark counterpart of the light shape that can be visually seen at the surface as both have matching dimensions. Closer examination of the paint topography using a stereomicroscope (see Fig. 1C) confirmed that a dark grey halo was applied in the underpainting, using a paint mixture that contains a carbon-based pigment that absorbs infrared radiation. This grey underlayer also has a visual impact on the appearance of the painting up until today: the blue sky directly adjacent to the woman seems lighter in color than the rest of the blue sky. This color difference is not due to overpaint or differences in varnish, but rather due to the local grey underpainting. In other areas of the blue sky, the reddish brown ground is visible through the upper paint layer, which has a visual impact on the blue color of the sky. This is not the case in the area of the dark grey halo, where the reddish brown ground is not visible through the upper paint layers, and thus doesn't have a visual impact on the light blue color of the sky. Upon considering all aforementioned aspects, it seems that Sweerts applied a dark grey halo in a wet medium during the early creation process but felt compelled to make efforts to hide its appearance in the final stages of painting. This peculiar technique and its use by Sweerts prompted more research into the phenomenon.

\section{Halos visible at the surface}

An albeit inexhaustive survey of paintings and exhibition catalogues revealed a significant number of Dutch and Flemish 17th-century paintings showing dark halos around the dramatis personae (see the table in Additional file 1). Examples are found in the oeuvres of influential artists such as Peter Paul Rubens (Figs. 3A, 7, 8, 9), Anthony Van Dyck (Fig. 5), Jan Steen (Fig. 3B), Peter Lely (Fig. 2A) and many others [4]. These occurrences can be divided in two groups: (1) unfinished paintings supplying us with an insight in the successive stages of the painting process and (2) finished paintings where an underlying halo can be seen through the top paint layer(s).

A prime example of the first group is Peter Lely's unfinished portrait of James II, shown in Fig. 2A. This canvas presents us with a 17th-century portrait as it looked immediately after the sittings were completed: the face of the sitter is finished, but the hair has only been suggested and the background still needs to be painted. Around the voluminous hair of James, a dark brown paint has been applied. According to Millar, who studied the painting, this dark brown halo is merely an indication of the finished background color, which is used in parallel 'to clarify the shape of the sitter's head' [5]. Other telling examples of unfinished paintings are Gilbert Stuart's Portrait of George Washington (Fig. 2B) and Jacques-Louis David's The Oath at the Tennis Court (Fig. 2C). As both paintings date from the eighteenth century, this indicates that the technique was still in use in the late $1700 \mathrm{~s}$ [6]. These three unfinished compositions are consistent with what was deduced from Sweerts' Peasant Family: halos are typically dark colored and prove to be part of the early paint stage. It is also important to note that the figure is not painted on top of the dark paint; the halo is applied around the outline of figure instead. This distinguishes the technique from a similar 17th-century painting practice observed in Dutch and Flemish flower still life paintings. In works by Jan Davidsz. De Heem, for example, flowers were painted on top of oval-shaped patches of underpaint, or dead-coloring, that anticipated the final color; this underpaint sometimes extend well beyond the eventual outlines of the flower petals. However, it is clear that this type of underpainting supplied a monochrome base color that significantly contributes to the deeply saturated colors of the end result $[7,8]$. In contrast, the halos in the 17th-century paintings presented here do not seem part of a sophisticated system 

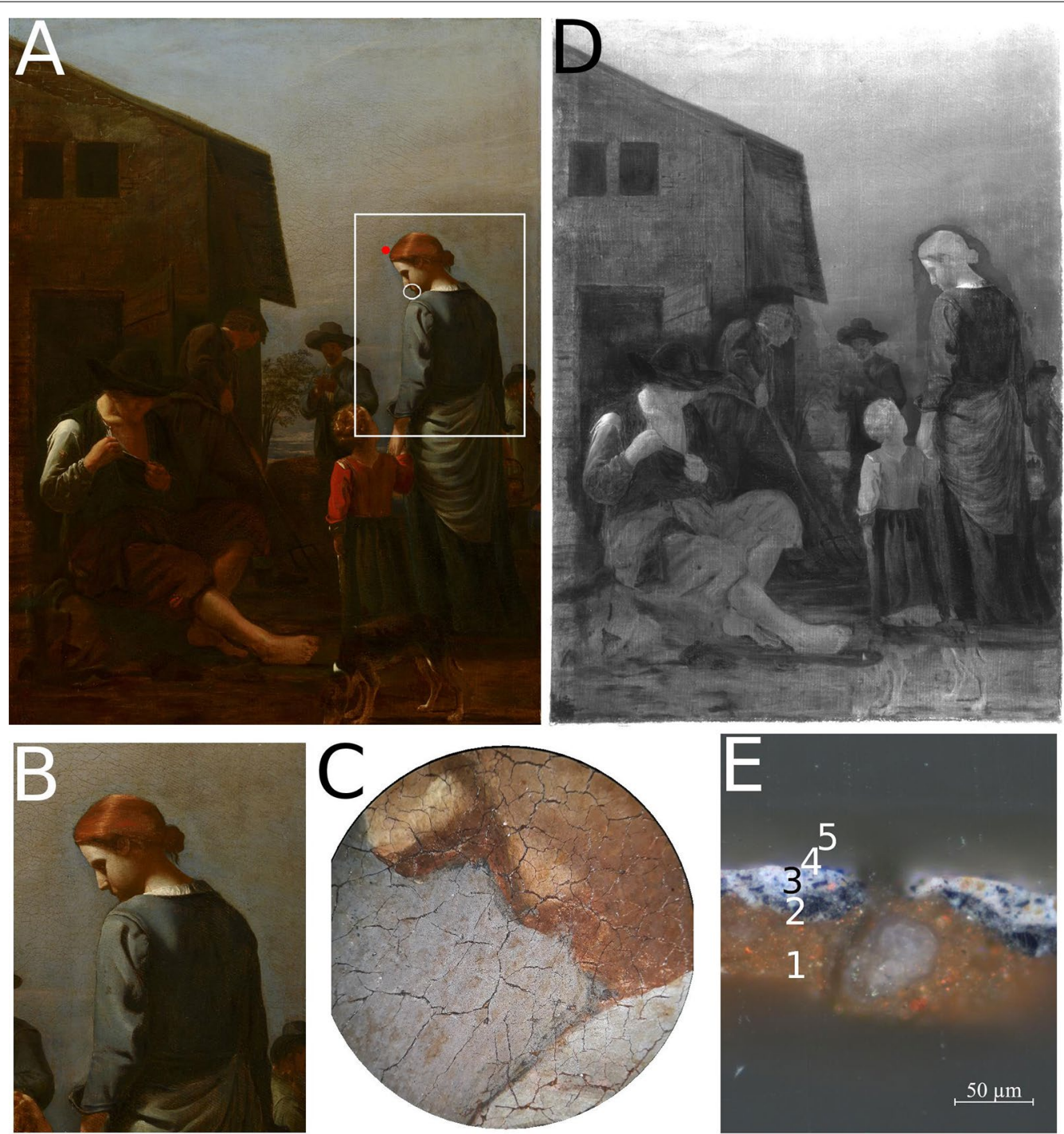

Fig. 1 A Michael Sweerts, Peasant Family with a Man Defleaing Himself, c. 1646-55. Oil on canvas, $66.5 \times 50$ cm. Mauritshuis (The Hague), inv.no. 886. The white rectangular indicates the detail area shown in $\mathbf{B}$. The white circle indicates the detail area shown in $\mathbf{C}$. The red dot indicates the area where the paint sample in $\mathbf{E}$ is taken. B Detail showing a shape applied with lighter paint around the mother figure. $\mathbf{C}$ Micrograph showing a detail of the face of the mother figure: a narrow aperture in between the paint of the face and the background sky provides a view to the underlying dark grey paint of the halo. $\mathbf{D}$ Infrared reflectogram revealing the presence of a carbon-based (thus dark) halo-like underpainting in the area of the light shape. $\mathbf{E}$ Microscopic image of a paint sample taken from the area of the halo. Three paint layers are present in this paint sample: (1) the reddish brown ground, (2) the grey paint layer used for the dark halo, consisting of lead white and a carbon black pigment (visually typical of charcoal), (3) the light blue paint layer of the sky, containing lead white, carbon black and a blue pigment (likely ultramarine). Layers 4 and 5 are varnish layers. Images courtesy of the Mauritshuis Museum. Photography by Margareta Svensson. Micrograph by Kirsten Derks. Infrared reflectogram made by Sarah Kleiner. Microscopic image of the paint sample made by Carol Pottasch

of semi-transparent paint strata, applied on top of each other in pursuit of yielding a distinctive optical quality to the superimposed layers. Dark halos typically do not continue underneath the figures. They seem to have a different function. The fact that Sweerts actually attempted to disguise their painterly effect, gives the idea that halos were instead a practical tool that helped him as he laid in the composition (discussed further below). As such, they appear to lose purpose once the artists proceed to the final brushwork, in a similar way as underdrawings, transfer grids and construction lines in 15th- and 16thcentury paintings.

Dark halos can also be seen through the upper paint layers of completed paintings. It has been noted in a few early works by Peter Paul Rubens: for example, on the right side of the sitter's face in Portrait of Roman Emperor 

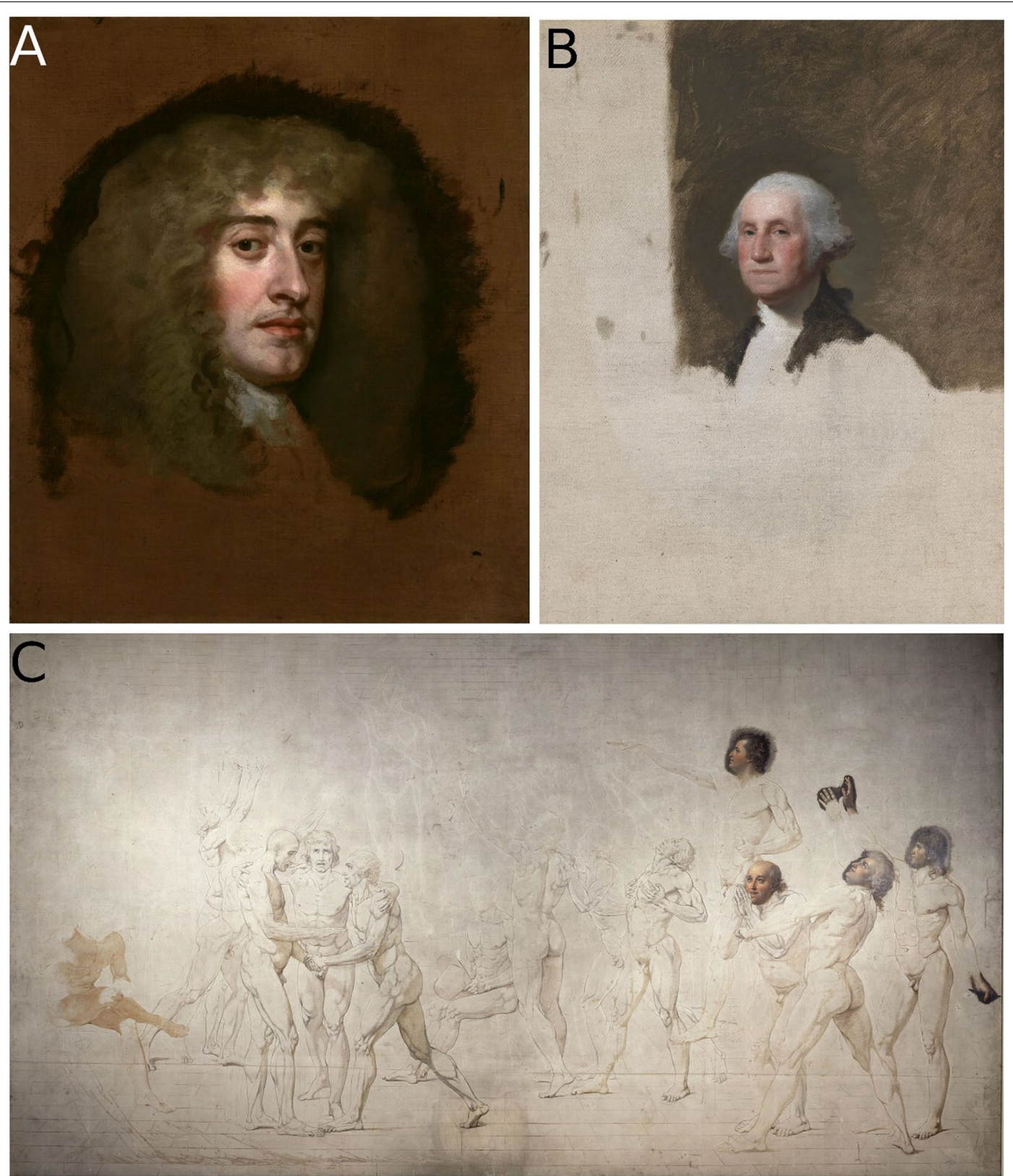

Fig. 2 Unfinished paintings displaying dark halos around the heads of the sitters. A Peter Lely, Portrait of James II when Duke of York, C. 1665-70. Oil on canvas, $51.4 \times 45.1 \mathrm{~cm}$. National Portrait Gallery (London), inv.no. NPG5211. Image: ONational Portrait Gallery London. B Gilbert Stuart, George Washington (The Athenaeum Portrait), 1796. Oil on canvas, $121.9 \times 94 \mathrm{~cm}$. National Portrait Gallery, Smithsonian Institution; owned jointly with Museum of Fine Arts (Boston), inv.no. NPG.80.115. Image courtesy of the National Portrait Gallery. C Jacques-Louis David, Oath at the Tennis Court, 1791-92. Oil, black chalk and bistre on canvas, $370 \times 654 \mathrm{~cm}$. Musée National de Château de Versailles, inv.no. MV5841. Image from the Google Art Project: see https://artsandculture.google.com/asset/fAEROKI7k5kYEQ

Aulus Vitellius from c. 1618-1619 (Fig. 3A), around the hand of Thomas in the central panel of the triptych The Incredulity of Saint Thomas from 1613-15 (Fig. 8) and around the foot of Venus and the back of Amor in Venus Frigida from c. 1614 (Fig. 9). More examples where dark halos can be seen with the naked eye are Johannes
Cornelisz. Verspronck's The Regentesses of the Saint Elisabeth's Hospital (Fig. 3C) [9] and Jan Steen's The Ill Woman (Fig. 3B) [10].

Most halos are found outlining human figures, and most often the face of these figures. Nevertheless, some artists also applied it along the contours of animals or 

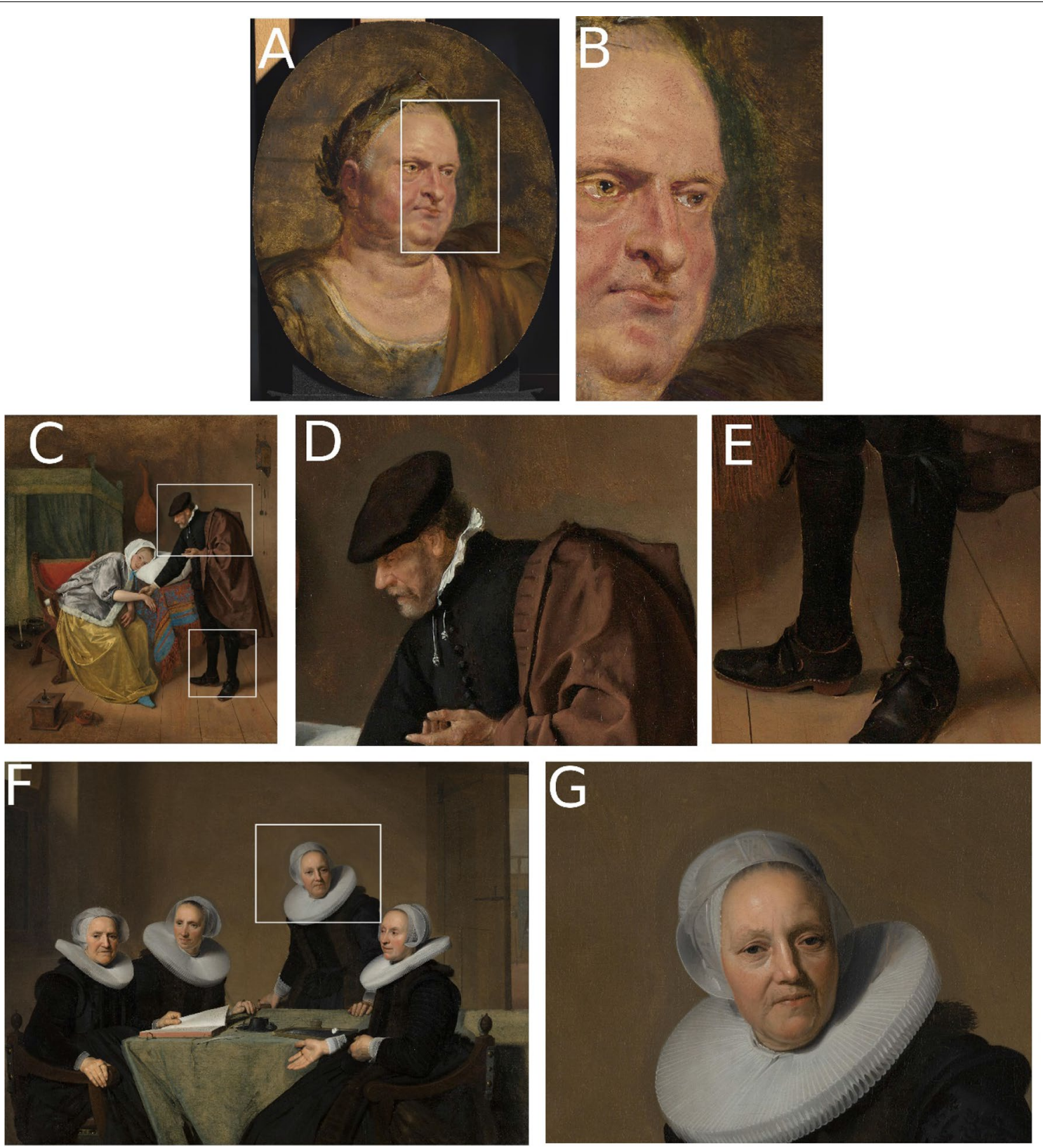

Fig. 3 A Peter Paul Rubens, Portrait of Roman Emperor Aulus Vitellius, c. 1618-19. Oil on panel, $33.3 \times 26.7 \mathrm{~cm}$. Private collection, Europe. The white rectangle indicates the area of the detail shown in B. B Detail showing a dark halo along the contour of Aulus Vitellius'face. Images courtesy of Salomon Lilian, Amsterdam. C Jan Steen, The III Woman, c. 1663-66. Oil on canvas, $76 \times 63.5 \mathrm{~cm}$. Rijksmuseum Amsterdam, inv.no. SK-C-230. The white rectangles indicate the areas of the details shown in $\mathbf{D}$ and $\mathbf{E}$. D Detail showing a dark halo around the doctor. $\mathbf{E}$ Detail showing a dark halo around the legs of the doctor. Images courtesy of the Rijksmuseum. F Johannes Cornelisz. Verspronck, Regentesses of the St. Elisabeth's Hospital in Haarlem, 1641. Oil on canvas, $156.9 \times 214.7 \mathrm{~cm}$. Frans Hals Museum, inv.no. os1-622. The white rectangle indicates the area of the detail shown in G. G Detail showing a dark halo along the head of one of the regentesses. Images courtesy of the Frans Halsmuseum. Photography by Margareta Svensson

inanimate objects. An example is Frans Francken the Younger's Art Cabinet with Scholars around a Globe (Fig. 4A), where a dark halo can be seen along the head and body of the dog in the foreground. Another example is Pieter Codde's A Painter in his Studio, Tuning a Lute (Fig. 4B). In this painting, Codde not only applied a halo around the male figure, but also along (the neck of) the cello on the right side of the composition. In all the 

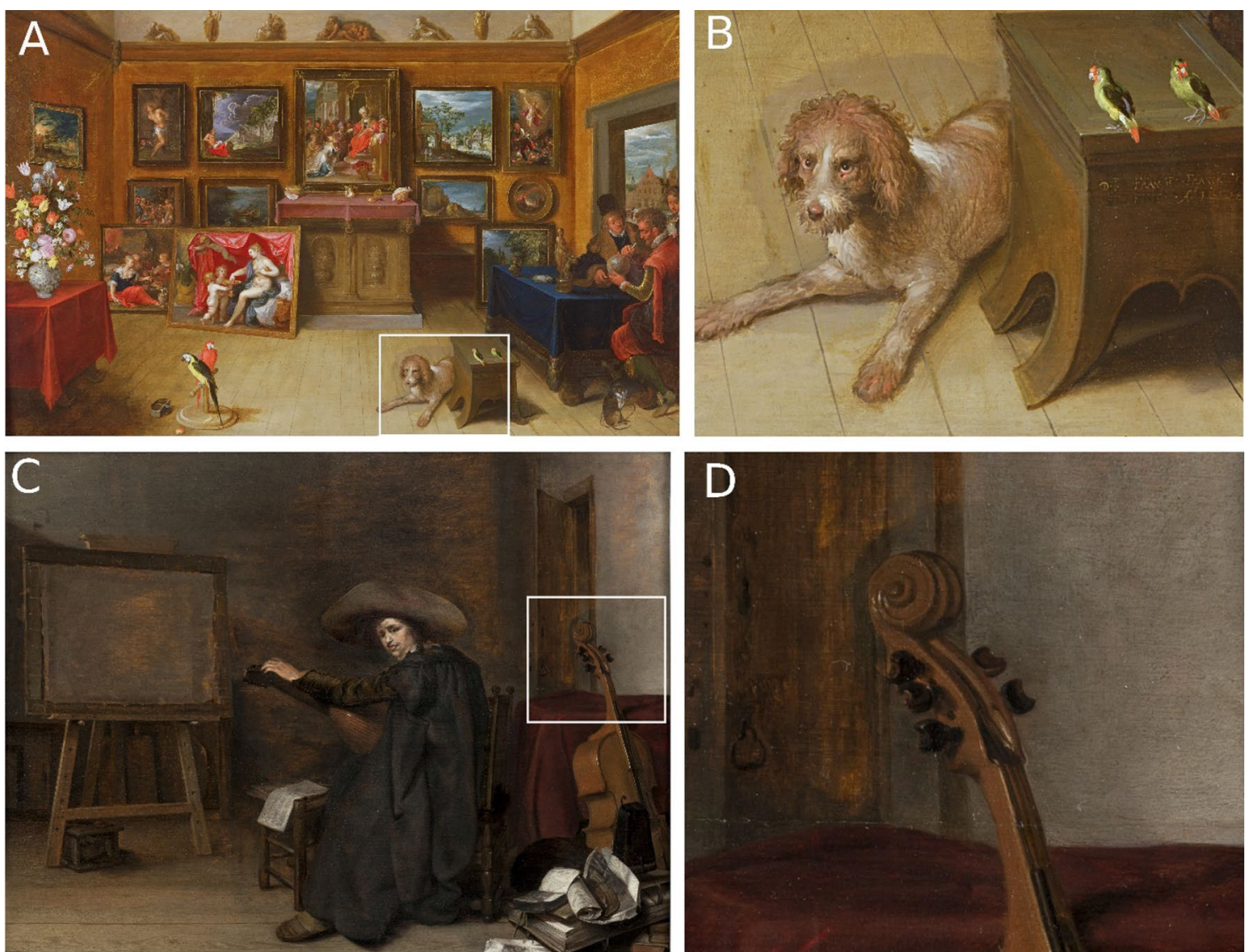

Fig. 4 Paintings displaying a dark halo around animals or inanimate objects. A Frans Francken the Younger, Art cabinet with Scholars around a Globe, 1612 . Oil on panel, $89.2 \times 109.2 \mathrm{~cm}$. Private collection. The white rectangle indicates the area of the detail shown in B. B Detail of the dark halo around the dog. Permission to use image pending. C Pieter Codde, A Painter in his Studio, Tuning a Lute, 1629(?). Oil on panel, $41 \times 54 \mathrm{~cm}$. Salomon Lilian (Amsterdam). The white rectangle indicates the area of the detail shown in $\mathbf{D}$. $\mathbf{D}$ Detail showing the dark halo around the top part of the cello. Permission to use image pending

aforementioned examples, the halo might not have been visible on the finished painting at the time of its creation. It is a well-known phenomenon that paint layers become more transparent over time, due to the saponification of oil paint containing lead, and the ensuing increase in the refractive index [11].

\section{Revealing hidden halos with imaging techniques}

The above-mentioned examples, stemming from a brief and preliminary survey of which the list is provided in the Additional file 1 below, suggest that a significant number of dark halos would be readily recognized, if paintings from this era are to be systematically examined with an eye for this phenomenon. Nevertheless, since additional halos surface upon studying technical imagery such as infrared reflectograms (IRR) or photographs (IRP), we believe that a substantial number still remain to be noticed by scholars. For instance, infrared examination of Anthony Van Dyck's paintings at the National Gallery
London revealed dark halos in several of his paintings, as briefly discussed by Roy in 1999 [12]. One of the clearest examples is Van Dyck's portrait of Lord John Stuart and his Brother, Lord Bernard Stuart (c. 1638-9, Fig. 5). The techniques used by Van Dyck in this life-size portrait are characteristic of his late portraits: all painterly attention is devoted to the figures and the draperies. The background is left in a rather sketchy state. Nevertheless, the IRP (see Fig. 5C) of this painting reveals a dark oval patch that stops near the neck of Lord Bernard's head, still wellconcealed by the overlaid brown background wash.

Underlying halos can only be detected using IRR and IRP if they are rich in infrared-absorbing pigments such as carbon black and, to a lesser extent, earth colors. Even so, the typical build-up of 17th-century paintings often proves unfavorable for distinguishing halos using IRR, as both the preparation below the halo and the superimposed pictorial paint often contain similar pigments. In this way, the characteristic abundance of carbon blacks 

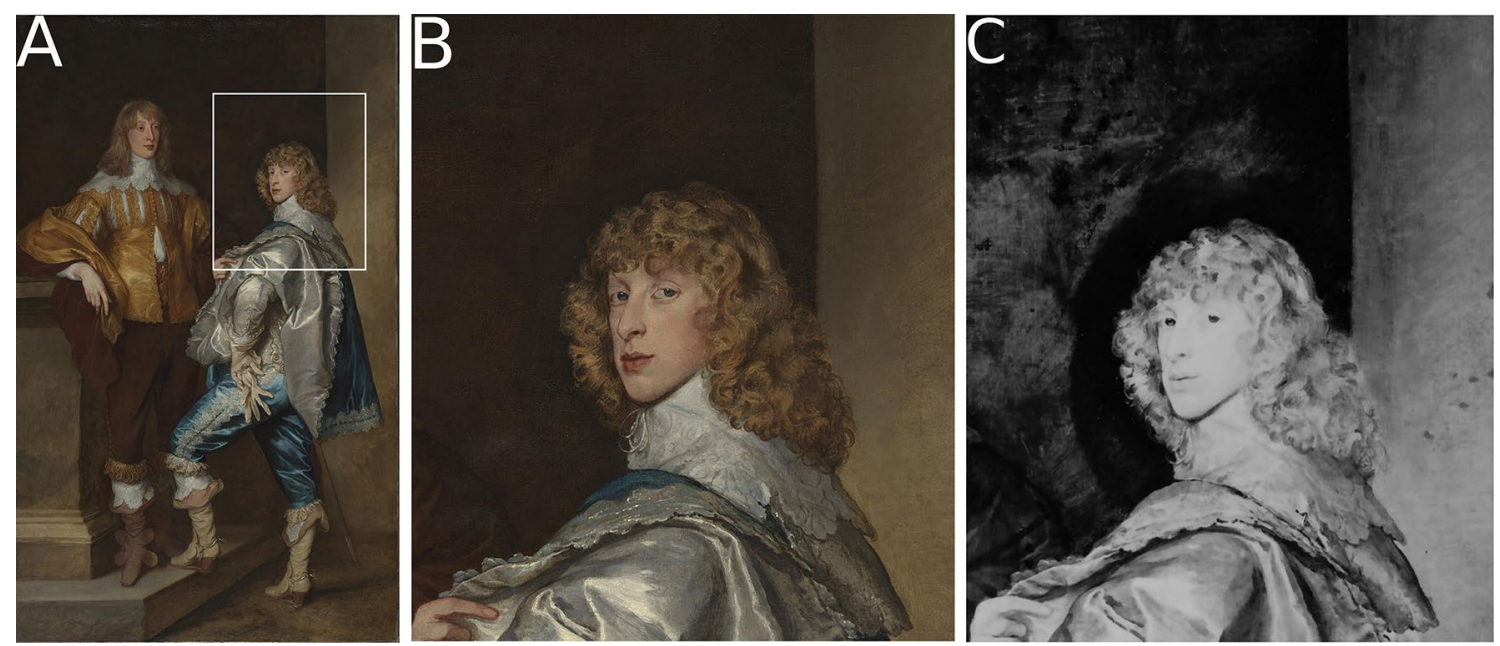

Fig. 5 A Anthony Van Dyck, Portrait of Lord John Stuart and his Brother Lord Bernard Stuart, c. 1638. Oil on canvas, $237.5 \times 146.1 \mathrm{~cm}$. National Gallery (London), inv.no. NG6518. The white rectangle indicates the detail area shown in B and C. Permission to use image pending. B Detail of Lord Bernard Stuart. C Matching detail of the infrared photograph showing a dark halo along the head of Lord Bernard Stuart. Images courtesy of the National Gallery London

and dark umbers or sienna's in the top layers inhibits the propagation of both the primary and reflected nearinfrared radiation throughout the paint stack, whereas a lack of reflection by the tinted grounds further reduces the contrast in the ensuing imagery. In this context, Van der Snickt et al. recently demonstrated the complementarity of MA-XRF imaging with IRR and XRR for studying 17th-century paintings in general and by Rubens in particular [13]. Unlike IRR, the occurrence of carbon and iron-based materials leaves the surface paint relatively transparent for X-ray radiation, while MA-XRF is sensitive towards halos potentially containing other pigments.

The added value of MA-XRF for studying halos is clearly illustrated by Sweerts' A Game of Backgammon and $A$ Game of Draughts, none of which have a halo that is visible to the naked eye (Figs. 6 and 11). In the latter work, only one halo emerges in the IRR, around the little boy in the center of the composition (see Fig. 6B). When examined using MA-XRF scanning, halos surrounding all figures can be visualized, but the dark background prevents them from being visible in the infrared imagery. In contrast, MA-XRF successfully visualizes the hidden halos in the elemental distribution maps of iron, manganese, potassium and lead (Fig. 6C-F). It should be noted that each halo seems to have been painted with a slightly different paint mixture, as the signal intensity of the elements differ from halo to halo. All contain iron, but only the halo framing the head of the boy pointing towards the door emerges in the lead map, whereas the halo around the head of the boy in the bright red uniform seems comparatively richer in manganese.
All halos appear in negative in the calcium map, i.e. as pixels with a lower grayscale due to a lower signal intensity. This negative correlation is indicative of a so called 'shielding effect' [14], suggesting that the detected calcium signals stem from an underlying, uniformly applied calcium-rich layer (e.g. the ground). The fluorescent radiation from $\mathrm{Ca}$ is proportionally more attenuated (thus shielded) by the locally applied paint layer of the halos. As a result, the halos show up as 'shadows' of the calcium signal in this elemental map, at the same time indicating that calcium-based pigments (such as bone black) are probably absent in the paint mixture of the halos.

In addition to showing that MA-XRF scanning is an essential diagnostic tool in revealing the full extent of the halo technique, MA-XRF scanning of $A$ Game of Draughts shows that Sweerts used slightly different paint mixtures for halos within the same work. It remains hitherto unclear if this distinction was purposefully made by Sweerts (and other artists, see Fig. 7) or if it is a unintended effect e.g. due to the reuse of heterogeneous palette scrapings or brush cleaning sediment for underpainting. The latter is an assumed studio practice by Rembrandt $[15,16]$ and Rubens (e.g. for his renowned streaky imprimatura) that is in line with the 17th-century economical way of painting.

\section{The function of dark halos}

Although halos can be found in a substantial number of 17th-century Dutch and Flemish paintings, the topic has so far received little attention in technical literature. Paintings conservator Martin Bijl reported a halo 

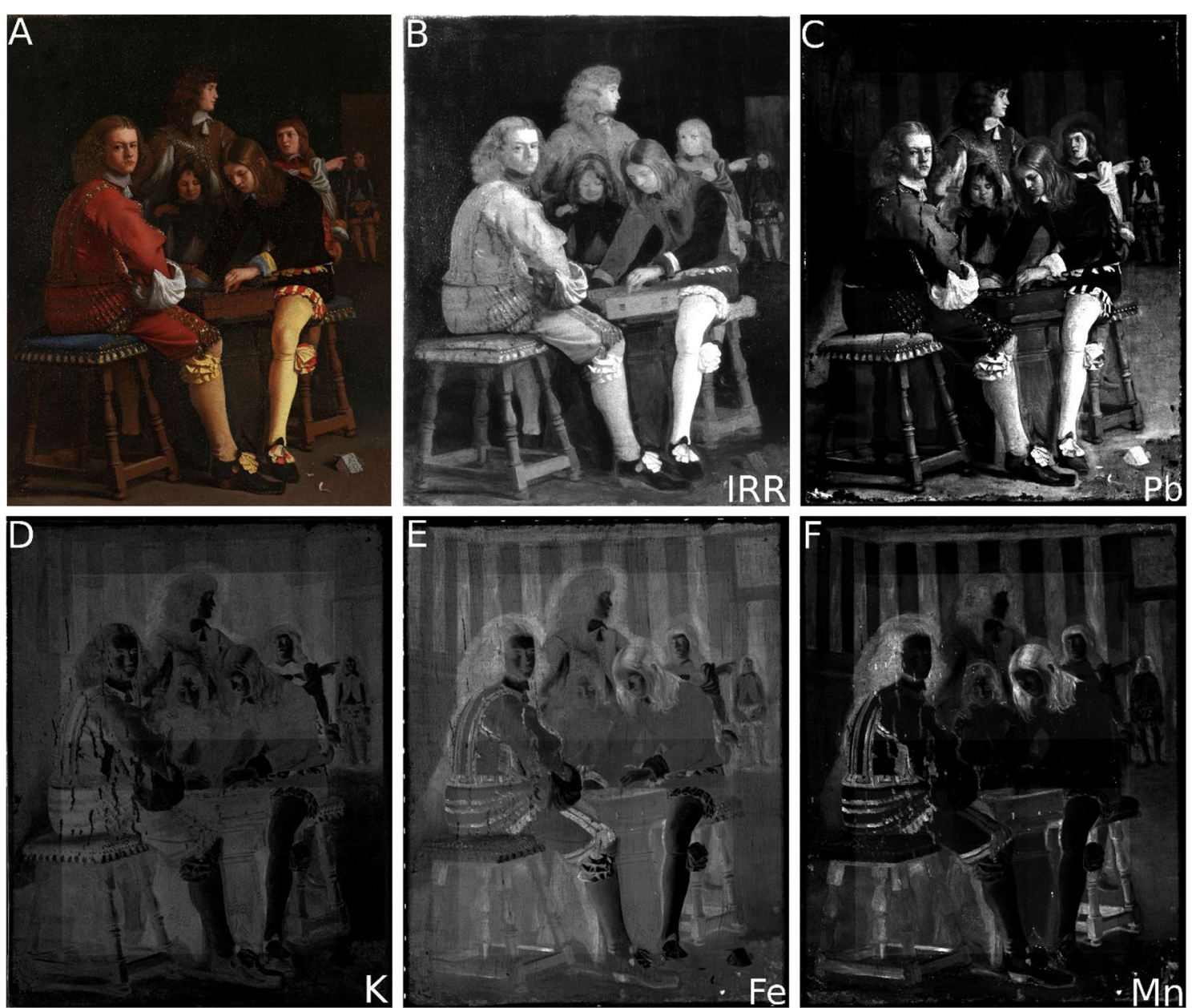

Fig. 6 A Michael Sweerts, A Game of Draughts, 1652. Oil on canvas, $48.6 \times 38.1 \mathrm{~cm}$. Mauritshuis (The Hague), inv.no. 1121. Image courtesy of the Mauritshuis Museum. Photography by Margareta Svensson. B Infrared reflectogram, showing a halo around the head of the little boy in the center of the composition. Infrared reflectography by Julianna Ly. C-F Elemental distribution images from MA-XRF. C Pb-L map. D K-K map. E Fe-K map. F Mn-K map. MA-XRF can successfully visualize hidden halos. From the different maps, it can be concluded that each halo seems to have been painted with a slightly different paint mixture, as the signal intensity of the elements differ from halo to halo

in Steen's The ill woman (Fig. 3B) in a 1996 exhibition catalogue [10], describing it as a characteristic element of Steen's painting style of the late 1650s. In view of the aforementioned occurrences in the oeuvre of different artists working in different painting styles and genres, it is now clear that the dark halo technique cannot be regarded as part of an artist's personal painting style. On the contrary, this albeit understudied technique seems rather an established element in the genesis of a 17thcentury composition.

In a 1996 paper, Jørgen Wadum mentioned corrections in paintings by Rubens, executed in a dark material and with broad brushstrokes [17]. With IRR, dark outlines along the contours of the figures were detected (see Fig. 7A-E). Wadum interpreted these broad brushstrokes as corrections to the figures; it is known that Rubens inspected and corrected the paintings before they left his studio. However, this hypothesis was refuted by Nico Van Hout in his doctoral dissertation. It seems unlikely that dark halos are corrections, as it seems that there is no paint layer present underneath this dark paint. Additionally, the dark halos were applied in the underpainting stage. According to Van Hout, making such bold corrections in the underpainting stage seems rather unnecessary and not very typical of Rubens [18].

In the aforementioned 20th National Gallery Technical Bulletin (1999), Roy suggested that Van Dyck employed halos as an aid to define the exact placement of the figures in the composition during the underdrawing stage. Along with the double portrait in Fig. 5, Roy adds The 

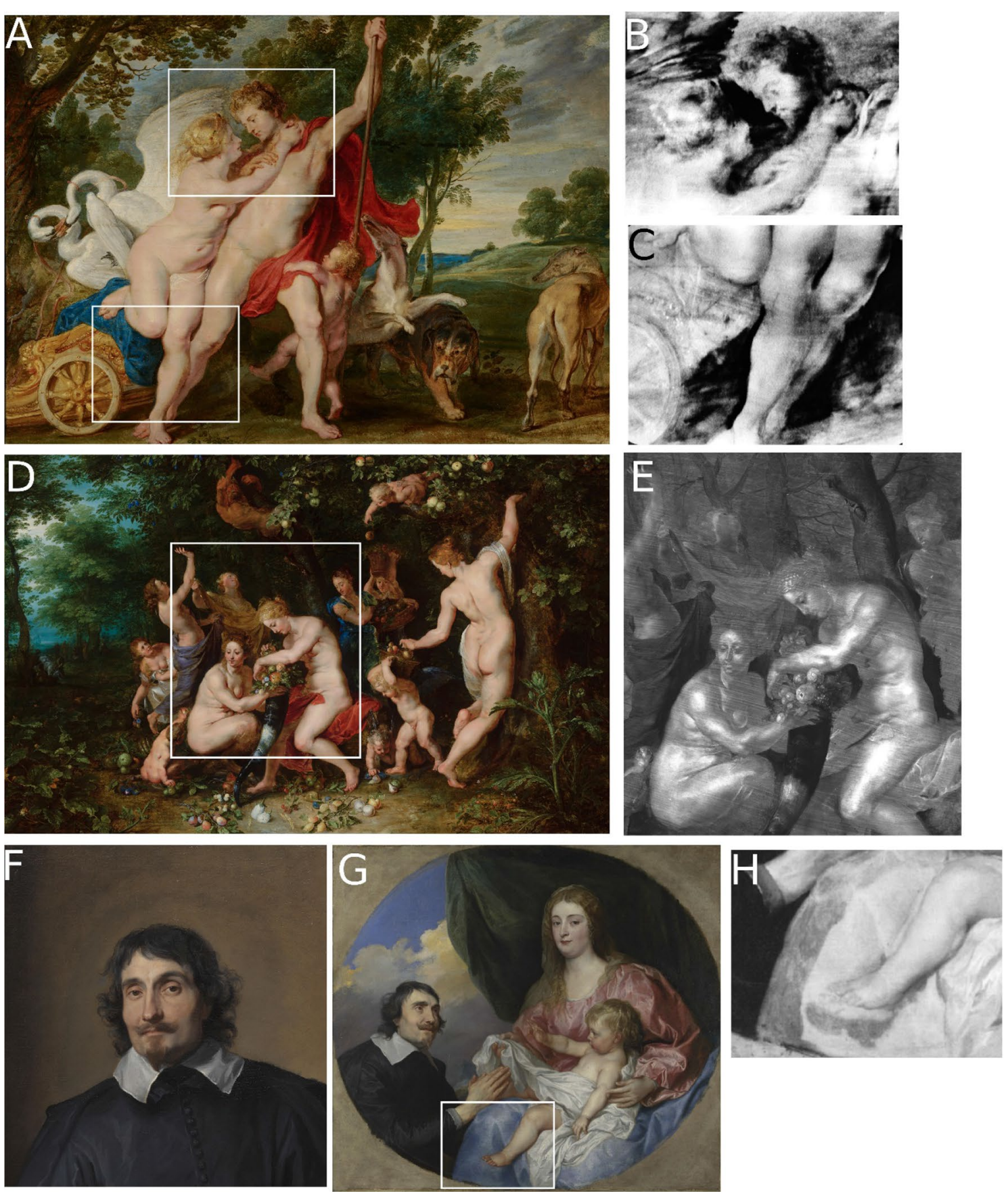

Fig. 7 A Peter Paul Rubens (studio copy), Venus trying to restrain Adonis from departing for the hunt, c. 1600-1700. Oil on panel, $59 \times 81 \mathrm{~cm}$. Mauritshuis (The Hague), inv.no. 254. The white rectangles indicate the areas of the details shown in $\mathbf{B}$ and $\mathbf{C}$. Image courtesy from the Mauritshuis Museum. Photography by Margareta Svensson. B IRR of a detail of Rubens'Venus trying to restrain Adonis. C IRR of a detail of Rubens'Venus trying to restrain Adonis. (Source: Wadum [17]). D Peter Paul Rubens and Jan Brueghel the Elder, Nymphs Filling the Cornucopia, c. 1615. Oil on panel, $67.5 \times 107 \mathrm{~cm}$. Mauritshuis (The Hague), inv.no. 234. The white rectangle indicates the area of the detail shown in $\mathbf{E}$. Image courtesy of the Mauritshuis Museum. Photography by Margareta Svensson. E IRR of a detail of Rubens' Nymphs Filling the Cornucopia. (Source: Wadum 17). F Anthony Van Dyck, Portrait of the Abbé Scaglia (detail), 1634. Oil on canvas, $200 \times 123 \mathrm{~cm}$. National Gallery (London), inv.no. NG6575. Around the head of the sitter, a dark halo can be seen through the upper paint layers. Image courtesy of the National Gallery (London). G Anthony Van Dyck, The Abbé Scaglia adoring the Virgin and Child, 1634-35. Oil on canvas, $106.7 \times 120 \mathrm{~cm}$. National Gallery (London), inv.no. NG4889. The white rectangle indicates the area of the detail shown in $\mathbf{H}$. Image courtesy of the National Gallery (London). $\mathbf{H}$ IRP of a detail of Van Dyck's The Abbé Scagllia adoring the Virgin and Child. Around the foot of the child, a dark halo can be seen. Image courtesy of the National Gallery (London) 

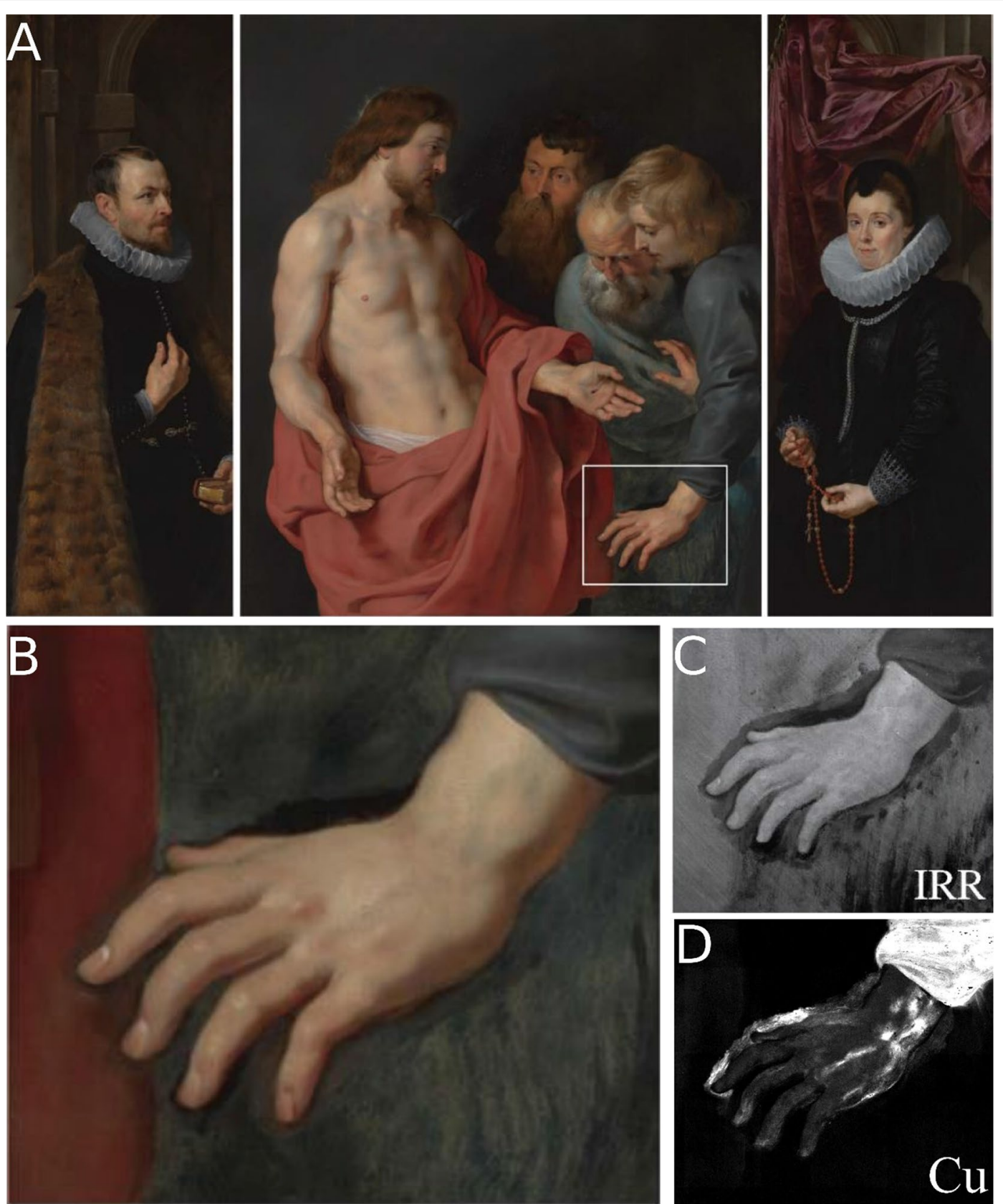

Fig. 8 A Peter Paul Rubens, The Incredulity of Saint Thomas, c. 1613-15. Oil on panel, $146 \times 233 \mathrm{~cm}$. Royal Museum of Fine Arts (Antwerp), inv. no. 307-311. B Detail showing a dark outline around the hand of Thomas. Images courtesy of the Royal Museum of Fine Arts Antwerp. C Infrared reflectogram of Thomas' hand. Image courtesy of the Royal Museum of Fine Arts Antwerp. D MA-XRF Cu-K Map, showing the dark halo in the underpainting contains a copper-based pigment

Abbé Scaglia adoring Virgin and Child and Portrait of the Abbé Scaglia as examples (see Fig. 7F-H) [12]. This hypothesis does not clarify in a satisfactory way why the artist would have abandoned the established and more efficient practice of (slimmer) markings in a dry and/ or wet medium for these purposes, which are easier to cover up. As attested by Sweerts Peasant Family, the halo might require additional efforts in the final stages of the painting process to mask or diminish its impact on the eventual visual appearance of the painting.

Nico Van Hout [19], on the other hand, argues that Rubens would have turned this potential optical effect to 

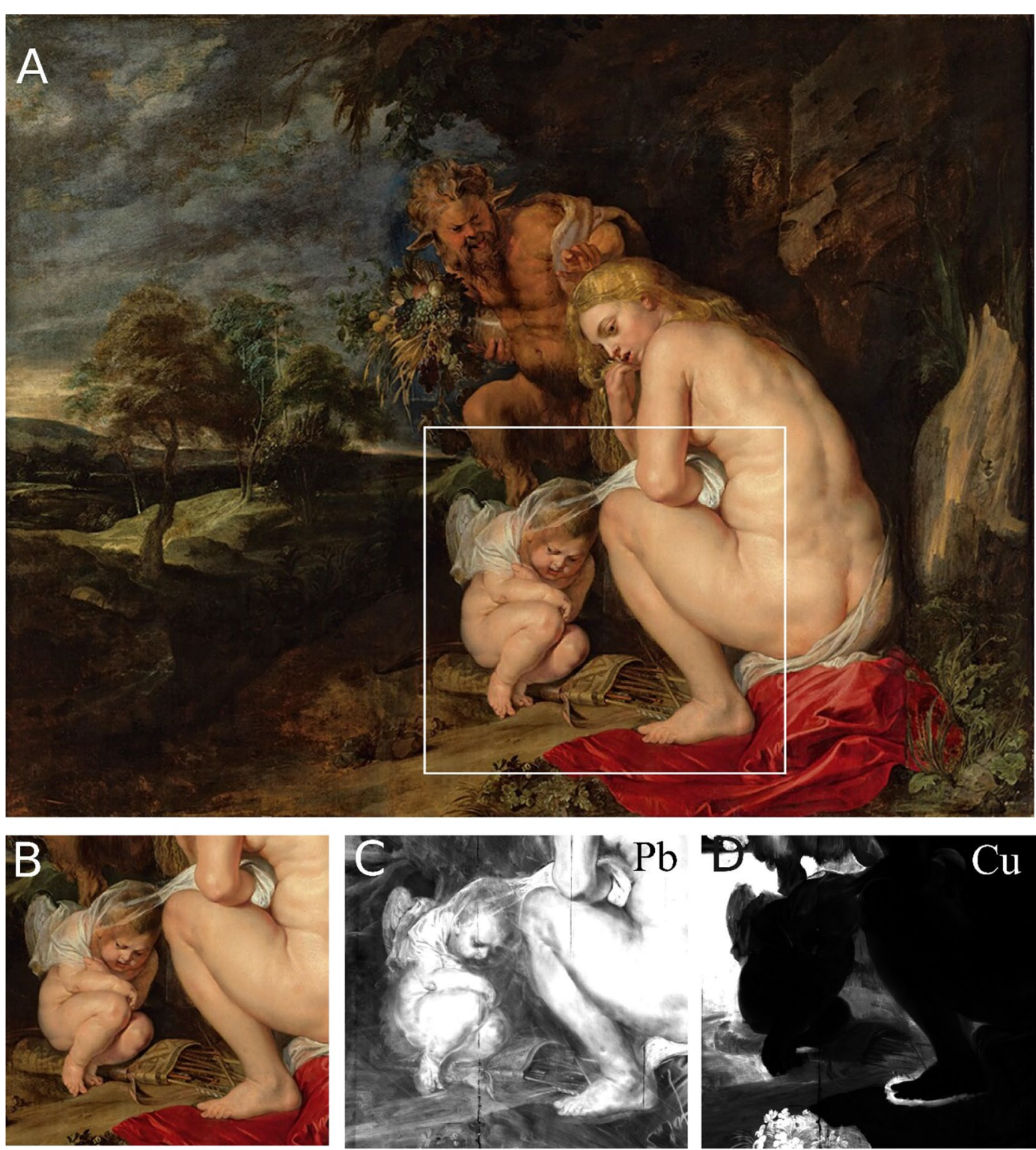

Fig. 9 A Peter Paul Rubens, Venus Frigida, 1614. Oil on panel, $143 \times 184 \mathrm{~cm}$. Royal Museum of Fine Arts (Antwerp), inv.no. 709. Image courtesy of the Royal Museum of Fine Arts Antwerp. B Detail. C PbL map displaying a lead-rich halo around the foot of Venus. D Cu-K map showing that the aforementioned halo is also rich in copper

the better, by proposing that the artist would have incorporated the halos consciously to emphasize certain elements (e.g. hands) in the composition. By using these dark halos, Rubens would have been able to indicate areas that were supposed to be underpainted and clearly distinguish them from areas where the imprimatura needed to play an visual role $[18,19]$. In addition, by placing darker tones directly adjacent to lighter areas such as flesh tones, the sense of depth was enhanced in the composition. This line of reasoning was underpinned by Van der Snickt et al. in [13], discussing the MA-XRF results on the aforementioned Incredulity of Saint Thomas (see Fig. 8). By placing a dark halo around Thomas' hand, Rubens might have wanted to draw the eye of the viewer to the hand that plays an important role in the biblical story. This double function makes sense in the context of Rubens' efficient brushwork, where he wanted to achieve an optical effect that works best when experienced from a distance; however, it remains unclear to what extent the halo was visible at the surface of the painting at the time of its creation, considering the aforementioned tendency of oil paint to become more transparent over time. In 
addition, this theory does not entirely stand up for works by Rubens that currently exhibit halos. For instance, it seems unlikely that in Venus Frigida, the halos around the backside of Amor and around Venus' foot were applied to draw the attention to these parts, since they lack iconographical importance (Fig. 9). Also, the tonality of the surrounding surface paint already appears to provide for the necessary contrast. Bearing in mind the prevalence of the halos in many other oeuvres, it seems more likely that Rubens had a different motivation for working with these subtle pictorial elements. Interestingly, Rubens' early works of the 1610s are the earliest examples of the halo technique reported so far. As such, the question arises if the highly influential artist with his many assistants and students, and an intellectual spill-over was the artist who introduced, or at least disseminated the dark halo technique in Flemish and Dutch Baroque painting [20]. If this is the case, the question remains whether he (or any other resourceful colleague) picked up this practice during his time in Italy upon studying the work of contemporary or preceding colleagues, or if he developed this approach himself.

Ella Hendriks supplied the most plausible theory when discussing the working methods of Johannes Cornelisz. Verspronck. She rationalized the technique as a way to provide a "foil against which the tones of the portrait could be established" [9]. With this dark halo applied along the contours of the face of the sitter, an artist could establish the correct highlights, midtones and shadow tones right away. We would like to build on Hendriks' hypothesis: we argue that the halo serves as a color reference in the earliest painting stage, when no tonal benchmark was available to the artist [21].

The latter principle is probably best grasped when looking at David's unfinished Oath at the Tennis Court in Fig. 2C. This notion might also justify the emergence of halos in 17th-century painting, and not earlier, in 15th- or 16th-century painting. This because the 17th-century way of painting was different from the methods used by earlier artists. 15th- and 16thcentury artists typically worked from background to foreground, leaving reserves in anticipation of the main figures that were painted later. With this approach, artists applied plenty of colors to hold on to from the beginning: they had a tonal benchmark when painting the main figures. This tradition is abandoned in the seventeenth century, when artists reversed the working sequence: they may have started by painting the main figures, while later adding the background. Artists did not have a tonal benchmark when painting the main figures according to this painting method: the dark halo could serve as such a tonal benchmark. In this viewpoint, dark halos are also in line with the efficient studio practice of that era, as the sitter could approve the portrait prior to investing work in the rest of the painting. In addition, the halo indicated the final tonality of the background, which would allow a studio assistant to finish the remaining parts independently. This may definitely be the case for artists like Rubens, who was known for having a lot of assistants and students. However, not every artist had assistants. Michael Sweerts for instance, whose work is discussed below as a case study, is known to only have had one student throughout his career. The records of the Brussels painter's guild only mention Jean-Baptist Borremans, who was registered as an apprentice of Sweerts in 1657. No other assistants, students or apprentices are mentioned in the records of the guild [22]. It remains unknown whether Sweerts had an assistant or apprentice while working in Italy. The 17th-century also marks the period in which Dutch and Flemish artists transitioned from working on white or off-white grounds to (strongly) colored grounds [23]. Such a colored ground, ranging from (dark) grey, to brown and even red, could function as a midtone for the composition.

At the same time, a dark halo in the underpainting might serve a second, different function, which is specifically related to portrait painting. When painting a portrait, artists need to pay attention to so-called hard and soft lines. The outer contours of a face need to softly blend into the background in order to create three dimensionality and liveliness. To be able to achieve such a soft blend, it is necessary to add a (dark) halo around the face of the sitter. This means that a dark halo along the face of a sitter may not have only served as a color reference, but also helped the artist to achieve a naturalistic portrait, with convincing modelling and three dimensionality.

\section{Halos in the context of modern studies in visual perception}

Hendriks' hypothesis, that the technique is a way for the artist to provide a "foil against which the tones of the portrait could be established", seems very plausible. The dark halo likely has an optical effect on the adjacent colors, and with this technique Verspronck and his contemporaries were able to establish the final colors in the faces of his sitters, anticipating the effect of the unrealized dark, background. It appears that by introducing halos, 17th-century painters intuitively or empirically found a solution to optical phenomena that were only described much later. In 1839, Michel Eugène Chevreul, one of the founding fathers of modern color technology, demonstrated that our eye will exaggerate the difference between two colors when we look at them simultaneously 


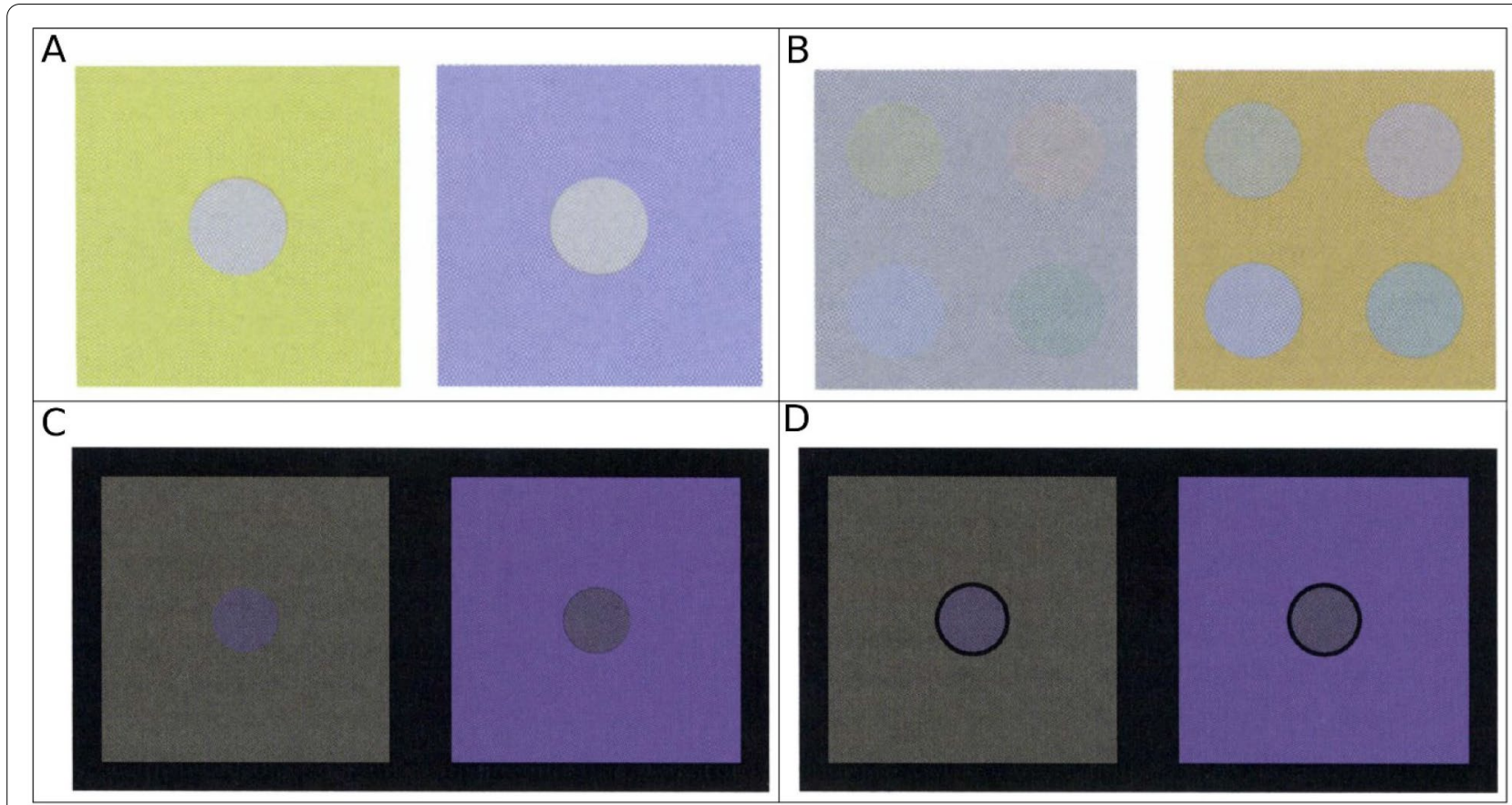

Fig. 10 Illustrations of the optical effects discussed in the present article. A Simultaneous contrast: the difference between two colors is exaggerated by our brain when we look at them simultaneously. B Crispening effect: different hues of the same color can be perceived better if the background is yet another hue of that same color. C No ring condition. D Ring condition. Source: Ekroll and Faul [25]

[24]. This means that whenever our eye sees two contiguous colors at the same time, they will appear to us as dissimilar as possible, both in their optical composition and in the strength of their color. This effect called 'simultaneous contrast', illustrated in Fig. 10A, has also been described by modern scholars of visual perception, although they describe this effect as happening in our brain instead of in our eyes. In fact, this phenomenon is a way for our brain to perceive colors better.

Related to simultaneous contrast is the so-called 'crispening effect'. This effect has been described in several visual perception studies: it refers to our observation that the apparent differences in color between similar targets is enhanced if the surround color is made more similar to the target colors $[25,26]$. In other words: we perceive different hues of the same color better if the background is yet another hue of that same color. This is demonstrated by Fig. 10B: the (slightly) different hues of purple of the targets can easier be differentiated against the purple background. If the same targets are seen against the yellowish background, the hues of the targets all appear more similar. In fact, the crispening effect is identical to and builds on the concept of simultaneous contrast.

Highly relevant for a good understanding of the historical halo technique is the so-called 'ring condition', a way to reduce or even abolish the simultaneous contrast or the crispening effect in an image. Experiments carried out in 2012 proved that the simultaneous contrast effect is reduced or abolished when a thin black outline separates the target color in the circle from the surround color [25]. The black outline in Fig. 10D acts as a border between the color of the target and its immediate surround and as such is a (neutral) resting point for the eye. As mentioned before, this black border reduces the simultaneous contrast: the color of the target seems more similar to the background color, whereas in Fig. 10C (where no black ring is present around the target) the color of the target appears more different from the background color. It is clear that, according this hypothesis, the dark halo in a 17th-century painting would function as the black ring separating the flesh tones of the sitter (target color) from the preparation (surrounding color). It seems that, centuries before these tests, artists experienced this unsolicited optical effect when taking up the baroque way of painting and adopted a solution for it.

\section{Halos in the oeuvre of Sweerts}

Upon returning and taking a closer look at the paintings that initiated this study, it seems likely that creative artists like Sweerts adapted the halo technique for their own needs and situations. In the Netherlands, artists usually worked on canvases prepared with a double, grey over red ground [23]. As Sweerts originated from Brussels, 

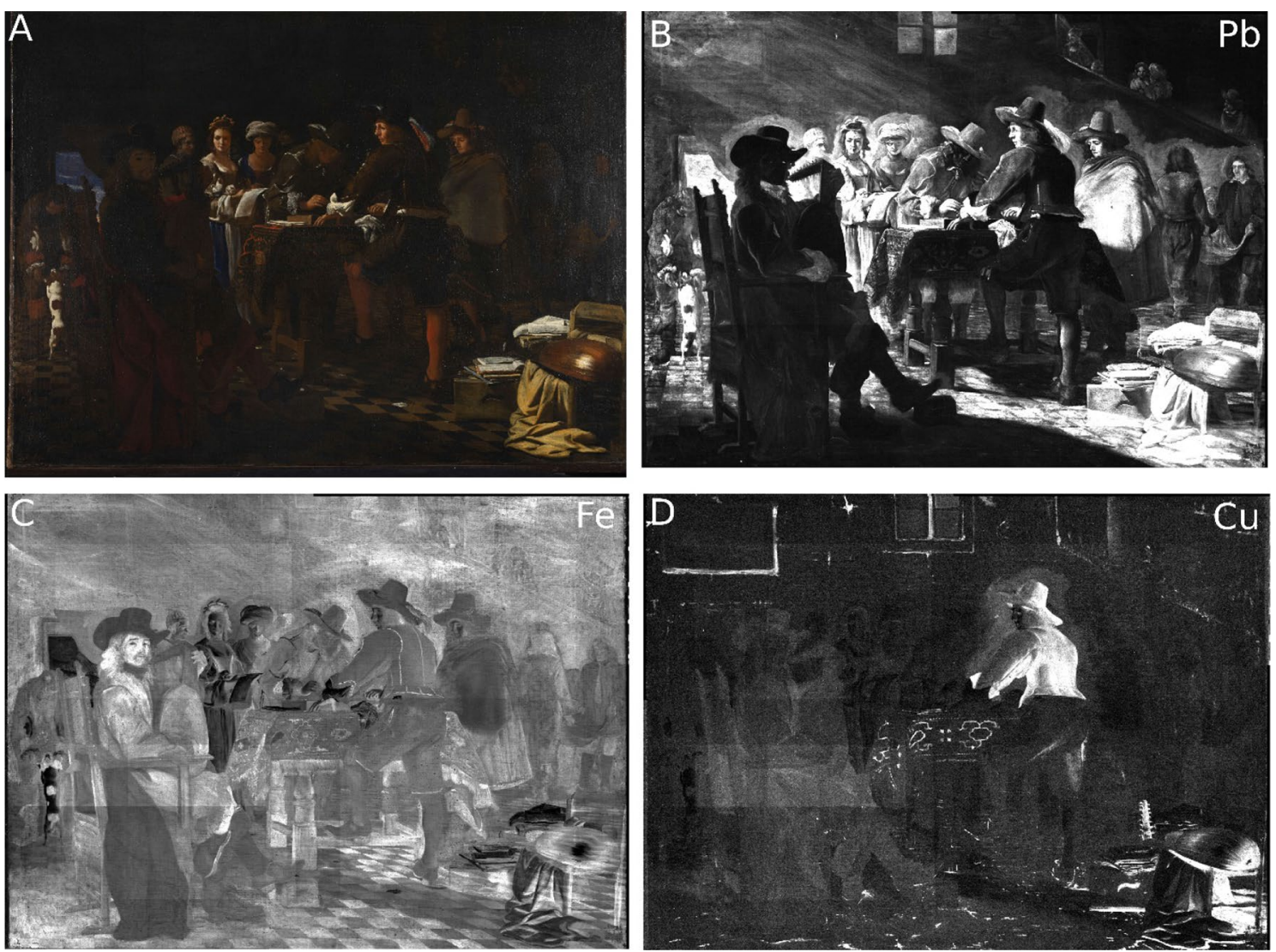

Fig. 11 A Michael Sweerts, a Game of Backgammon, c. 1646-54. Oil on canvas, $75 \times 100 \mathrm{~cm}$. Salomon Lilian (Amsterdam). Image courtesy of Studio Redivivus. B MA-XRF Pb-L map displaying several halos along the figures in the composition. C MA-XRF Fe-K map. This map shows that iron is present throughout the painting, indicating that the composition is painted on a reddish brown ground layer. D MA-XRF Cu-K map, displaying a copper-rich halo along the standing figure in the center of the composition. The broad horizontal bands visible in the left part of the Fe and $\mathrm{Cu}$ maps are scan artefacts resulting from the presence of the stretcher and easel (upon which the painting was scanned), causing the background in the XRF spectra to be more intense in some regions

he probably was trained to work on such grounds. When he moved to Rome, he adapted his working methods to the common Italian practice of employing a single reddish brown ground [27]. Although this aspect remains hitherto understudied in literature, it seems unlikely that Sweerts, or any other artist for that matter, was able to switch from a dark grey ground to a reddish brown ground with ease. It must have taken quite the effort to understand and anticipate the optical effect of the underlying warm color on various types of overlaid paint mixtures and brushwork. In this framework, it is interesting that all the Sweerts paintings in which halos were found so far, were painted on canvas prepared with a reddish brown ground and are attributed to his Italian period: Peasant Family, A Game of Backgammon and A Game of Draughts (see Figs. 1, 11 and 6). Although MA-XRF imaging attests that earth pigments are present in these halos (as they contain iron and manganese), microscopic examination of the paintings revealed that all dark halos exhibit a dark grey to black color. Although more research is needed, the question arises as to whether the grey halos were Sweerts' way of dealing with these different colored grounds. Perhaps, by adding these dark grey halos along the contours of the main figures in the composition, it was easier for Sweerts to assess what the final outcome of his applied colors would be.

Chevreul mentioned in his 1839 publication that a grey background is the only neutral background. As with other colors, black and white have a visual impact on the adjacent colors. Grey, however, makes the adjacent colors appear brighter and purer [24]. Although the phenomenon of simultaneous contrast was only described for the first time in the nineteenth century, that doesn't mean that artists may not have been aware of the optical effects colors have on each other. It is well possible that artists empirically knew about these mutual color effects and that they kept those ideas in mind while working on 
a painting. This might be the reason why Sweerts has seemed to favor a grey tone for his halos, as this would have no visual effect on the adjacent colors.

\section{Conclusions}

A brief survey highlighted the prevalence of dark halos around figures and objects in 17th-century Western European easel painting. A substantial number of examples where the halo can be seen through the surface paint has already been found, but the extent of this phenomenon is likely substantially larger than can be potentially estimated from such a study. Examination with technical imaging (i.e. IRP and IRR) and the complimentary MA-XRF experiments performed in the context of this paper revealed many additional halos below the surface. Presumably future examinations of paintings with these findings in mind might uncover more examples.

We reason that halos were an established part of the 17th-century painting practice, rather than a marginal or personal phenomenon. Unfinished paintings provide insight into the paint buildup; it becomes evident that halos were a compositional aid in the earliest painting stages and that, as a rule, they were not meant to be visible. The tendency of oil paint to become more transparent over time might have resulted in the unintended visibility of halos; however, it cannot be excluded that creative artists such as Rubens deliberately exploited their visibility for obtaining simultaneous optical effects from the time of the painting's creation. Its overall function can be clarified building on Hendriks' discussion of the technique in the oeuvre of Verspronck. In line with this theory we argue that the need for a halo arises when artists abandoned the 15-16th-century tradition of working from background to foreground. By starting from the main figures, the baroque artist had no tonal benchmark to anticipate the effect of the (often) dark background color. This was especially problematic for the subtle nuances in the flesh tones, and considering the accurate rendering of enhanced contrasts between light and shade, this becomes increasingly important throughout this era. We propose that halos are a response to optical effects that are described in modern studies of visual perception as simultaneous contrast and the crispening effect. The discussed ring condition explains how a dark ring (in this case the halo) neutralizes the unsolicited impact of the surround color (dark background) on a target color (e.g. flesh tone). As such, it seems that baroque painters empirically found a solution to an optical effect that was only demonstrated centuries later by optical science and labelled as a strategy of our brain to discern colors better. More research into historical textual sources might reveal to what extent the artists and scientists were implicitly aware of these optical effects. Finally, a closer look into Sweerts oeuvre suggests that artists might have experimented with halos and the underlying principles in a creative manner for their personal needs. In the case of Sweerts, he needed to deal with the impact of a different color of ground when he moved to Rome, where a warm reddish brown preparation was preferred over the more neutral grey-over-brown ground of the South Netherlandish painting tradition.

\section{Supplementary Information}

The online version contains supplementary material available at https://doi. org/10.1186/s40494-021-00634-w.

Additional file 1. A preliminary listing of paintings in which a halo has been observed.

\section{Acknowledgements}

The authors gratefully acknowledge the involved collections (the Mauritshuis and Redivivus Conservation) for the opportunity to examine the paintings by Michael Sweerts. We'd like to thank in particular Edwin Buijsen, Carol Pottasch, Abbie Vandivere, Julianna Ly, Sabrina Meloni, Gwen Boevé-Jones and Kimberly Frost. We would also like to thank Ella Hendriks, Sven Van Dorst, Nico Van Hout and Abbie Vandivere for reading and commenting on a first draft of this paper.

\section{Authors' contributions}

$\mathrm{KD}$ and GvdS wrote the main body of the text. KvdS and KJ read and commented on earlier versions of the manuscript. SL helped with processing the data and was vital for the maintenance of the equipment. All authors read and approved the final manuscript.

\section{Funding}

This research took place as part of a Ph.D. research project, funded by FWO (project no. G0D2618N) and was part of the activities of the Chair of Advanced Imaging Techniques of the Arts, established by the Baillet Latour Fund.

Availability of data and materials

The datasets used and analyzed during the current study are available from the corresponding author on reasonable request.

\section{Declarations}

Competing interests

The authors declare that they have no competing interests.

\section{Author details}

${ }^{1}$ Faculty of Arts, Research group Art History, KU Leuven, Blijde Inkomststraat 21, 3000 Leuven, Belgium. ${ }^{2}$ Faculty of Design Sciences, ARCHES Research Group, University of Antwerp, Mutsaardstraat 31, 2000 Antwerp, Belgium. ${ }^{3}$ Faculty of Science, AXIS Research Group, University of Antwerp, Groenenborgerlaan 171, 2020 Antwerp, Belgium.

Received: 16 September 2021 Accepted: 29 November 2021 Published online: 07 January 2022

References

1. For more information about the research project, see: https://researchpo rtal.be/en/project/screening-michael-sweerts-en-michaelina-wautieradded-value-advanced-imaging-characterising. The second artist studied in the $\mathrm{PhD}$ research project is Michaelina Wautier. 
2. Lighter colored halos have been mentioned in the oeuvre of Diego Velázquez and Jusepe de Ribera. See: Van Hout N. Functies van Doodverf. Leuven: PhD Dissertation: KU Leuven; 2005.

3. Multiple conservation reports as well as research reports mention the halo in Peasant Family with a Man Defleaing Himself. See documentation file MH_0866 in the archives of the Conservation Studio of the Mauritshuis.

4. For more paintings containing a dark halo, see the table in the Supplementary Information.

5. Millar O. Sir Peter Lely. London: National Portrait Gallery; 1978.

6. The dark halo technique seems to end in the 1700s. So far, the authors have found no examples of the technique in 19th-century paintings. However, this research has not been exhaustive.

7. De Keyser N, VanderSnickt G, VanLoon A, Legrand S, Wallert A, Janssens K. Jan Davidsz. De Heem (1606-1684): a technical examination of fruit and flower still lifes combining MA-XRF scanning, cross-section analysis and technical historical sources. Herit Sci. 2017. https://doi.org/10.1186/ s40494-017-0151-4.

8. Van Dorst S. Daniël Seghers, phoenix of flower-painters. Hamilton Kerr Institute Bulletin. 2016:6:29-44.

9. Hendriks E. Johannes Cornelisz. Verspronck. The Technique of a Seventeenth Century Haarlem Portraitst. In: Hermens E, editor. Looking Through Paintings (Leids Kunsthistorisch Jaarboek XI). Baarn and London: De Prom and Archetype Publications; 1998, 227-267.

10. Bijl M. Steens Werkwijze. In: Chapman HP, Kloek W, Wheelock AK, editors Jan Steen Schilder en Verteller. Amsterdam, Washington: Rijksmuseum and National Gallery of Art; 1996. p. 83-91.

11. Van Eikema Hommes M. Changing pictures. Discoloration in 15th-17thcentury oil paintings. London: Archetype Publication; 2004

12. Roy A. The national gallery Van Dycks, technique and development. Natl Gallery Tech Bull. 1999:20:50-83.

13. Van der Snickt G, Legrand S, Slama I, Van Zuien E, Gruber G, Van der Stighelen K, Klaassen L, Oberthaler E, Janssens K. In situ macro X-ray fluorescence (MA-XRF) scanning as a non-invasive tool top robe for subsurface modifications in paintings by PP Rubens. Microchem J. 2018;138:238-45.

14. Van der Snickt G, Martins A, Delaney J, Janssens K, Zeibel J, Duffy M, McGlinchey C, Van Driel B, Dik J. Exploring a hidden painting below the surface of René Magritte's Le Portrait. Appl Spectrosc. 2016. https://doi. org/10.1177/0003702815617123.

15. Alfeld A, Siddons DP, Janssens K, Dik J, Woll A, Kirkham R, Van de Wetering E. Visualizing the 17 th century underpainting in portrait of an old man by Rembrandt van Rijn using synchrotron-based scanning macro-XRF. Appl Phys A. 2013. https://doi.org/10.1007/s00339-012-7490-5.

16. Van de Wetering E. Rembrandt, the painter at work. Amsterdam: Amsterdam University Press; 1997.

17. Wadum J. A Preliminary Attempt to Identify Ruben's Studio Practice. ICOM Committee for Conservation 11th Triennial Meeting Edinburgh 1-6 September 1996. Edinburgh; 1996. p. 393-395.

18. Van Hout N. Functies van Doodverf. Leuven: PhD Dissertation: KU Leuven; 2005

19. Van Hout N, Balis A. Rubens doorgelicht: Meekijken over de schouder van een virtuoos. Brussels: Ludion; 2010

20. Jonckheere K. Another History of Art. Veurne: Hannibal; 2020.

21. It should be noted that in most paintings included in this study, the artist did not seem to have applied the dark halo technique consistently. In Verspronck's Regentesses of the St. Elisabeth's Hospital in Haarlem, a dark halo is visible around the heads and faces of only two of the sitters. Similarly, Sweerts applied a dark halo along the silhouettes of only two figures in his Peasant Family. Why artists didn't apply the technique consistently within one painting remains unclear. Further research is needed to answer this question.

22. The records of the Brussels guild have been digitized and made available through www.projectcornelia.be. This website is part of a research project of KU Leuven.

23. Stols-Witlox M. A perfect ground. Preparatory layers for oil paintings 1550-1900. London: Archetype Publications; 2017.

24. Chevreul ME. The principles of harmony and contrast of colour, and their applications to the arts. London: Longman; 1855.

25. Ekroll V, Faul F. Basic characteristic of simultaneous color contrast revisited. Psychol Sci. 2012. https://doi.org/10.1177/0956797612443369.
26. Whittle P. Brightness, discriminability and the "Crispening Effect."Vision Res. 1992;32-8:1493-507.

27. Wallert A, De Ridder W. The materials and methods of Sweerts's paintings. In: Jansen G, Sutton PC, editors. Michael Sweerts (1618-1664). Amsterdam: Rijksmuseum; 2002. p. 37-47.

\section{Publisher's Note}

Springer Nature remains neutral with regard to jurisdictional claims in published maps and institutional affiliations.

\section{Submit your manuscript to a SpringerOpen ${ }^{\circ}$ journal and benefit from:}

- Convenient online submission

$\checkmark$ Rigorous peer review

- Open access: articles freely available online

- High visibility within the field

- Retaining the copyright to your article

Submit your next manuscript at $\boldsymbol{\nabla}$ springeropen.com 